\title{
Choosing the proper size for sutureless prostheses
}

\author{
Michel Carrier, MD, MBA
}

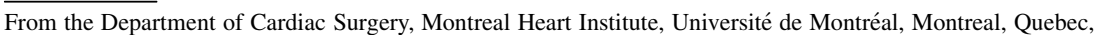
Canada.

Disclosures: Author has nothing to disclose with regard to commercial support.

Received for publication Sept 29, 2016; accepted for publication Sept 30, 2016; available ahead of print Nov 29 , 2016.

Address for reprints: Michel Carrier, MD, MBA, Department of Cardiac Surgery, Montreal Heart Institute, Head of the Department of Surgery, Université de Montréal, 5000 Belanger St, Montreal, Quebec H1T 1C8, Canada (E-mail: michel.carrier@icm-mhi.org).

J Thorac Cardiovasc Surg 2017;153:273-4 $0022-5223 / \$ 36.00$

Copyright (C) 2016 by The American Association for Thoracic Surgery http://dx.doi.org/10.1016/j.jtcvs.2016.09.079
}

Baert and colleagues ${ }^{1}$ report 4 cases of incomplete deployment and stent recoil of the sutureless Perceval valve (LivaNova, London, United Kingdom) in patients with a small aortic annulus. A smaller sutureless prosthesis was redeployed in 2 patients, and a standard valve was sutured in the other 2 patients.

Aortic valve replacement has greatly evolved during the last few years from standard stented bioprostheses, to transcatheter aortic valve replacement, and to surgical use of sutureless bioprostheses. The latter showed several clinical advantages, namely, shorter crossclamp, cardiopulmonary bypass, and total operating room times, and it greatly facilitates minimally invasive approaches. $^{2}$

Although the technique of implantation of a sutureless prosthesis remains fairly close to a standard valve replacement, several steps deserve attention. A higher aortic transverse aortotomy, correct sizing with both proper sizer and obturator after annulus decalcification, the use of 3 guiding sutures in the aortic annulus, deployment and ballooning of the prosthesis, and, last but not least, inspection of the prosthesis in place are required.

Two key points should address the particular problems described by Baert and colleagues. ${ }^{1}$ First is the selection of the proper size of prosthesis with the sizer and the obturator. For years, we have implanted the largest prosthesis possible in patients and enlarged the aorta and annulus if necessary. This paradigm does not hold with a sutureless valve. Focus should be on selection of the proper valve size with both a sizer and an obturator. It is simple: A prosthesis too small will leak and too big will not deploy correctly in the right position. Do not oversize!

Second, inspection of the valve after deployment is crucial, and one should answer the following questions. Are the coronary ostia patent and free of obstruction? Do I see the anterior leaflet of the mitral valve in opening the pericardial cusps of the prosthesis? Are the struts of the valve close to the aortic commissure? I also drop a few milliliters of methylene blue in each pericardial cusp to ensure

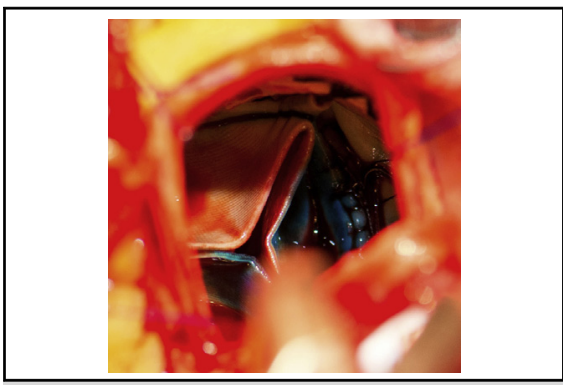

This is a well-seated sutureless prosthesis after methylene blue testing.

\section{Central Message}

For years, we have implanted the largest sutured prosthesis possible in patients. Focus should be on selection of the proper valve size with the new sutureless prosthesis.

See Article page 270.

that there is no leak beneath the valve (Figure 1). Do not neglect that step: It could save you time and effort!

Moreover, this sutureless prosthesis obviously is not held to the annulus with strong sutures. Thus, we should only manipulate the heart gently and with great care. If possible, I will not lift up the heart for deairing or for inspection after

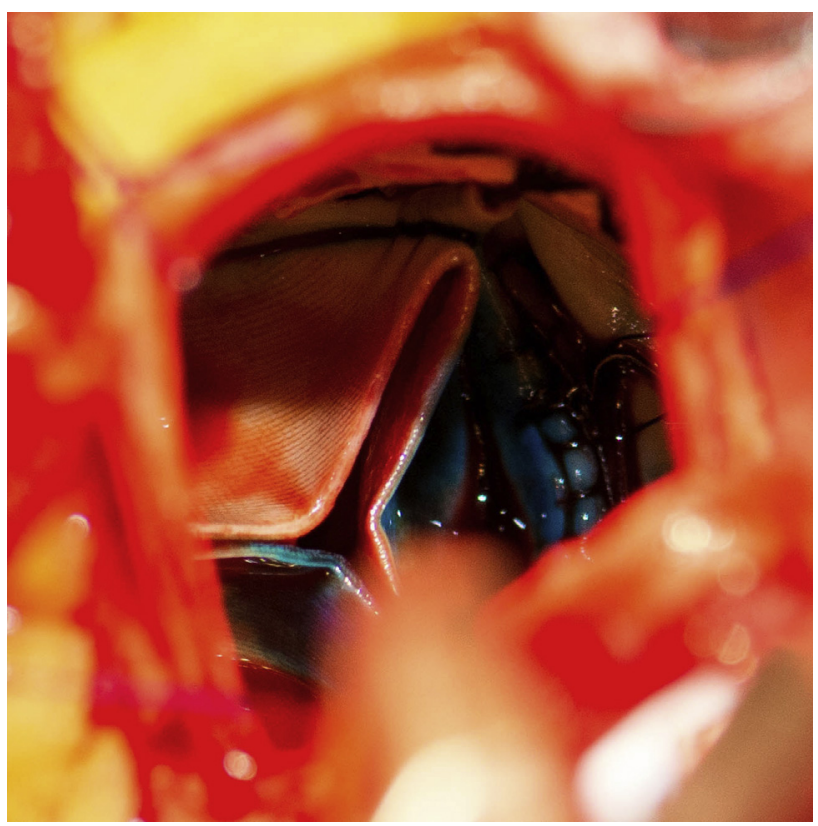

FIGURE 1. This is a well-seated sutureless prosthesis after methylene blue testing. 
closure of the ascending aortotomy. Do not kick the heart because the stent might recoil!

The technique of sutureless prosthesis implantation constantly evolves with clinical experience as reported by Baert and colleagues ${ }^{1}$ and Yanagawa and colleagues. ${ }^{3}$ The use of sutureless valves offers a unique opportunity to improve clinical results with surgical aortic valve replacement.

\section{References}

1. Baert J, Astarci P, Noirhomme P, de Kerchove L. The risk of oversizing with the Perceval S sutureless bioprosthesis in small aortic annulus. J Thorac Cardiovasc Surg. 2017; 153:270-2.

2. Forcillo J, Bouchard D, Nguyen A, Perrault L, Cartier R, Pellerin M, et al. Perioperative outcomes with sutureless versus stented biological aortic valves in elderly persons. J Thorac Cardiovasc Surg. 2016;151:1629-36.

3. Yanagawa B, Cruz J, Boisvert L, Bonneau D. A simple modification to lower incidence of heart block with sutureless valve implantation. J Thorac Cardiovasc Surg. 2016;152:630-2. 